\title{
LOSING SLEEP AT THE MARKET: AN EMPIRICAL NOTE ON THE DAYLIGHT SAVING ANOMALY IN AUSTRALIA
}

\author{
by \\ ANDREW C. WORTHINGTON
}

\section{Overview}

In a recent provocative article, Kamstra et al. (2000) found that the average Friday-toMonday stock return on daylight saving weekends was 200 to 500 percent larger than the average negative return for other weekends (the so-called 'weekend-effect' market anomaly) and thereby associated with a one-day loss of US\$31 billion on the NYSE, AMEX and NASDAQ markets alone. Kamstra's et al. (2000) findings appeared to hold not only in the United States and Canada, where the transition to and from daylight saving is broadly similar, but also in the United Kingdom, whose patterns differ from that in North America, and to a lesser extent in Germany. On this basis, Kamstra et al. (2000, p. 1010) suggested that if daylight saving was associated with "...the sort of impact investigated here, an obvious policy implication is to do away with the time change altogether".

The essence of Kamstra's et al. (2000) argument is that the 'daylight saving effect' is linked with sleep desynchronosis associated with the change in the circadian rhythm and its (negative) impact on sleep patterns. Every Spring at 2:00 a.m. on the first Sunday in April US clocks are moved forward one hour, and the following Fall at 2:00 a.m. on the last Sunday in October clocks are moved back one hour. As with jet lag, where changes in sleep patterns are thought to persist up to five days for each one-hour time zone crossed (Waterhouse et al. 1997), the movement to daylight saving time (DST) also compresses the day, while the movement from daylight saving stretches it, and this also impacts upon sleep patterns.

If, and as hypothesised by Kamstra et al. (2000, p. 1006), “...sleep desynchronosis causes market participants to suffer greater anxiety about a given situation, ceteris paribus, they may prefer safer investments and shun risk in trades during the trading day following such a disturbance in their sleep patterns...this could push down stock prices following daylight saving shifts when the desynchronosis is systematic". In fact, the argument that shifts to and from daylight saving has an impact upon actual behaviour already has parallels elsewhere with Bick and Hannah (1986) and Shapiro et al. (1990) studying the impact of DST on psychiatric presentation, and Coren (1996a, 1996b) Lambe and Cummings (2000), Varughese and Allen (2001) and Sullivan and Flannagan (2002) examining its role in traffic and pedestrian accidents.

School of Economics and Finance, Queensland University of Technology. The author would like to thank Siv Taing for research assistance and Helen Higgs and an anonymous referee for helpful comments on an earlier version of the article.

Author Posting. (c) The Authors 2003. This is the author's version of the work.

It is posted here for personal use, not for redistribution. The definitive version was published in

Economic Papers, 22(4), pp.83-93. 
All the same, there are a number of complications associated with Kamstra's et al. (2000) purported daylight saving effect, which may not arise in non-financial market contexts. To start with, the daylight saving effects exists in parallel with the oftexamined weekend effect, for which a number of competing hypotheses have already been put forward and tested (see, for instance, Agrawal and Ikenberry 1994, Chang et al. 1993, 1998 and Wang and Erickson, 997). The weekend effect has already been linked to lags in the payment and cheque clearing settlements, to midweek time pressures on individuals, the tendency for financial advice to be given after Monday strategy-setting meetings, and to the larger percentage of purchases (sales) on Fridays (Mondays) at dealer ask (bid) prices (Kamstra et al. 2000). It may then be possible that the sleep desynchronosis associated with daylight saving weekends is just an alternative manifestation of this more usual market anomaly. For example, Pinegar (2002, p. 1256) countered that "the change in sleeping patterns from weekdays to weekends occurs with much greater frequency and is very plausibly more pronounced than the change in sleeping patterns between daylight-saving and non-daylight saving weekend. Thus sleep desynchronosis may contribute to the so-called 'day-of-the-week' effect on nondaylight saving Mondays also".

Another problem is that daylight saving transition weekends are by nature limited in number, and these may be juxtaposed with outliers. Once again, Pinegar (2002) questioned Kamstra's et al. (2000) conclusions on the basis that in the last eighty years three of the largest percentage declines in the S\&P 500 took place after a fall daylightsaving time change (most recently Monday 26 October 1987). In response, Kamstra et al. (2002, p. 1263) countered, “... while we do not believe that daylight-saving-time changes cause market crashes, we do believe that daylight-saving-time changes affect the degree of market fluctuations... we speculate that severe downturns are more likely following daylight-saving weekends, and we argue that the data support this contention" (original emphasis). Lastly, Pinegar (2000) also argues that the apparent corroboration offered by Kamstra's et al. (2000) inclusion of Canada, Germany and the United Kingdom in their analysis may be an illusion associated with the normal influence on them by the US market, and that such international evidence should then be treated more cautiously.

The purpose of the present article is to add to this small but intriguing body of work the results of an analysis of the Australian equity market. To the author's knowledge this is the first of its kind in Australia, and adds significantly to the nascent literature concerning the economic benefits and costs of daylight saving. The article itself is divided into four main areas. Section 2 discusses the starting and ending dates of DST in Australia since 1979/80. Section 3 explains the empirical methodology and data collection employed in the analysis. Section 4 presents the results. The article ends with a brief conclusion.

\section{Daylight Saving in Australia}

Two dates are relevant for the implementation of DST in Australia: (i) a Sunday a.m. starting date, usually in late October, and (ii) a Sunday a.m. ending date, normally in late March in the following year. However, one complication that does exist in Australia is that not all states and territories currently use DST, and of those that do the 
TABLE 1

IMPLEMENTATION DATES OF DAYLIGHT SAVING TIME WITHIN AUSTRALIA, 1979/80 - 2002/03

\begin{tabular}{|c|c|c|c|c|c|c|c|c|c|c|c|c|c|c|c|c|}
\hline \multirow[b]{2}{*}{ Year } & \multicolumn{2}{|c|}{ NSW } & \multicolumn{2}{|c|}{ VIC } & \multicolumn{2}{|c|}{ QLD } & \multicolumn{2}{|c|}{ SA } & \multicolumn{2}{|c|}{ WA } & \multicolumn{2}{|c|}{ TAS } & \multicolumn{2}{|c|}{$\mathrm{ACT}$} & \multicolumn{2}{|c|}{ Total } \\
\hline & Start & End & Start & End & Start & End & Start & End & Start & End & Start & End & Start & End & Start & End \\
\hline $1979-80$ & 28-Oct & 2-Mar & 28-Oct & 2-Mar & - & - & 28-Oct & 2-Mar & - & - & 28-Oct & 2-Mar & $28-\mathrm{Oct}$ & 2-Mar & 1 & 1 \\
\hline $1980-81$ & 26-Oct & 1-Mar & 26-Oct & 1-Mar & - & - & 26-Oct & 1-Mar & - & - & 26-Oct & 1-Mar & 26-Oct & 1-Mar & 1 & 3 \\
\hline $1981-82$ & 25-Oct & 4-Apr & 25-Oct & 7-Mar & - & - & $25-\mathrm{Oct}$ & 7-Mar & - & - & 25-Oct & 28-Mar & $25-\mathrm{Oct}$ & 7-Mar & 1 & 2 \\
\hline $1982-83$ & 31-Oct & 6-Mar & 31-Oct & 6-Mar & - & - & $31-$ Oct & 6-Mar & - & - & 31-Oct & 27-Mar & $31-\mathrm{Oct}$ & 6-Mar & 1 & 1 \\
\hline $1983-84$ & 30-Oct & 4-Mar & 30-Oct & 4-Mar & - & - & 30-Oct & 4-Mar & 30-Oct & 4-Mar & 30-Oct & 4-Mar & 30-Oct & 4-Mar & 1 & 1 \\
\hline $1984-85$ & 28-Oct & 3-Mar & 28-Oct & 3-Mar & - & - & $28-O c t$ & 3-Mar & - & - & 28-Oct & 3-Mar & $28-O c t$ & 3-Mar & 1 & 1 \\
\hline $1985-86$ & 27-Oct & 16-Mar & 27-Oct & 16-Mar & - & - & 27-Oct & 16-Mar & - & - & 27-Oct & 2-Mar & 27-Oct & 16-Mar & 1 & 2 \\
\hline $1986-87$ & 19-Oct & 15-Mar & 19-Oct & 15-Mar & - & - & 19-Oct & 15-Mar & - & - & 19-Oct & 15-Mar & 19-Oct & 15-Mar & 1 & 1 \\
\hline $1987-88$ & 25-Oct & 20-Mar & $25-\mathrm{Oct}$ & 20-Mar & - & - & 25-Oct & 20-Mar & - & - & $25-\mathrm{Oct}$ & 20-Mar & $25-\mathrm{Oct}$ & 20-Mar & 1 & 1 \\
\hline $1988-89$ & 30-Oct & 19-Mar & $30-O c t$ & 19-Mar & - & - & 30-Oct & 19-Mar & - & - & $30-O c t$ & 19-Mar & $30-O c t$ & 19-Mar & 1 & 1 \\
\hline $1989-90$ & 29-Oct & 4-Mar & 29-Oct & 18-Mar & 29-Oct & 4-Mar & 29-Oct & 18-Mar & - & - & 29-Oct & 18-Mar & 29-Oct & 4-Mar & 1 & 2 \\
\hline 1990-91 & 28-Oct & 17-Mar & 28-Oct & 3-Mar & 28-Oct & 17-Mar & 28-Oct & 3-Mar & - & - & 28-Oct & 3-Mar & $28-O c t$ & 17-Mar & 1 & 2 \\
\hline 1991-92 & 27-Oct & 1-Mar & 27-Oct & 1-Mar & 27-Oct & 1-Mar & 27-Oct & 22-Mar & 27-Oct & 1-Mar & 27-Oct & 27-Oct & 27-Oct & 1-Mar & 1 & 3 \\
\hline $1992-93$ & 25-Oct & 7-Mar & 25-Oct & 7-Mar & - & - & $25-\mathrm{Oct}$ & 7-Mar & - & - & 4-Oct & 7-Mar & $25-\mathrm{Oct}$ & 7-Mar & 2 & 2 \\
\hline 1993-94 & 31-Oct & 6-Mar & 31-Oct & 6-Mar & - & - & $31-O c t$ & 20-Mar & - & - & 31-Oct & 27-Mar & $31-\mathrm{Oct}$ & 6-Mar & 2 & 3 \\
\hline 1994-95 & 30-Oct & 5-Mar & 30-Oct & 26-Mar & - & - & 30-Oct & 26-Mar & - & - & 2-Oct & 26-Mar & $30-O c t$ & 5-Mar & 2 & 3 \\
\hline $1995-96$ & 29-Oct & 31-Mar & 29-Oct & 31-Mar & - & - & 29-Oct & 31-Mar & - & - & 1-Oct & 31-Mar & 29-Oct & 31-Mar & 2 & 1 \\
\hline 1996-97 & 27-Oct & 30-Mar & 27-Oct & 30-Mar & - & - & 27-Oct & 30-Mar & - & - & 6-Oct & 30-Mar & 27-Oct & 30-Mar & 2 & 1 \\
\hline $1997-98$ & 26-Oct & 29-Mar & 26-Oct & 29-Mar & - & - & 26-Oct & 29-Mar & - & - & 5-Oct & 29-Mar & 26-Oct & 29-Mar & 2 & 1 \\
\hline 1998-99 & 25-Oct & 28-Mar & $25-\mathrm{Oct}$ & 28-Mar & - & - & $25-$ Oct & 28-Mar & - & - & 4-Oct & 28-Mar & $25-\mathrm{Oct}$ & 28-Mar & 2 & 1 \\
\hline 1999-00 & 31-Oct & 26-Mar & 31-Oct & 26-Mar & - & - & 31-Oct & 26-Mar & - & - & 3-Oct & 26-Mar & 31-Oct & 26-Mar & 2 & 1 \\
\hline 2000-01 & 27-Aug & 25-Mar & 27-Aug & 25-Mar & - & - & 29-Oct & 25-Mar & - & - & 27-Aug & 25-Mar & 27-Aug & 25-Mar & 2 & 1 \\
\hline 2001-02 & $28-O c t$ & 31-Mar & $28-O c t$ & 31-Mar & - & - & $28-O c t$ & 31-Mar & - & - & 7-Oct & 31-Mar & $28-O c t$ & 31-Mar & 2 & 1 \\
\hline $2002-03$ & 27-Oct & 30-Mar & 27-Oct & 30-Mar & - & - & 27-Oct & 30-Mar & - & - & 6-Oct & 30-Mar & 27-Oct & 30-Mar & 2 & 1 \\
\hline
\end{tabular}

Source: Commonwealth Bureau of Meteorology (2003). Notes: NSW - New South Wales, VIC - Victoria, QLD - Queensland, SA - South Australia, WA Western Australia, TAS - Tasmania, ACT - Australian Capital Territory. The Northern Territory has never implemented Daylight Saving Time. Start starting date of Daylight Saving Time, end - ending date of Daylight Saving Time. In all cases listed the change to Daylight Saving Time took place at 0200 hours Local Standard Time on the day concerned, and from Daylight Saving Time to Local Standard Time at 0300 hours. All transitions to and from DST are on Sundays. Total is the number of different start and end dates across the states and territories in each year. 
timing and adherence to the usual starting and ending dates has varied over the sample period. As shown in Table 1, of Australia's six states and two territories only New South Wales (NSW), Victoria (VIC), South Australia (SA), Tasmania (TAS) and the Australian Capital Territory (ACT) have implemented DST annually since 1979/80, while Queensland (QLD) and Western Australia (WA) adopted DST spasmodically, from 1989/90 to 1991/92 and in 1983/84 and 1991/92, respectively. The Northern Territory (not shown) has never used DST. In order to reflect these differences in the current analysis, two sets of starting dates and three sets of ending dates are identified.

The first set of starting dates is where the most populous states of NSW and VIC both shift to DST at the same time. These account for 24 cases in the 24 years in the sample and on most occasions include many of the remaining states and territories. The second set is when a state or territory other than NSW or VIC commences DST on some other date. This represents 11 cases in 24 years. The other set of dates is the DST ending dates and these comprise three categories: (i) occasions when NSW and VIC shifted from DST at the same times (19 cases), (ii) dates when NSW and VIC moved out of DST at different times (4 cases in each respect) and (iii) dates when a state or territory other than NSW and VIC shifted out of DST at a different time to NSW and VIC (8 cases). As before, at least some other states and territories may also have moved out of DST at these times. Accordingly, in the twenty-four year sample there have been thirty-five weekends in Australia where DST started at 2:00 a.m. on Sunday and thirty-five weekends where DST ended on Sunday at 3:00 a.m.

\section{Research Method and Data}

To test for the economic effect of daylight saving time change we look at the first trading day following the transition to or from DST. The data employed in the study are market returns drawn from the Australian Stock Exchange (ASX) over the period 2 January 1980 to 5 May 2003. Both the All Ordinaries Price and Accumulation (including dividends and capitalisation changes) Indices are used. Following Kamstra et al. (2000, 2002) and Pinegar (2002) a series of daily raw returns are calculated of which three categories are identified. These are: (i) a weekend return calculated from the Friday and Monday closing prices for weekends that do not include a DST starting or ending Sunday, (ii) a DST starting and ending weekend return calculated using the Friday and Monday closing prices for weekends including a DST starting or ending Sunday, and (iii) other days being those other than DST and non-DST weekends. The DST starting and ending weekends are further categorised according to the different sets of starting and ending dates discussed above.

The basic hypothesis examined in this analysis is that the change to DST impacts upon sleep patterns in such a way that the daily returns for the next trading day following such a transition will differ from other days. This is because the starting of DST is associated with a loss of one hour during the day while the movement from DST adds an hour. Further, since the transition to (and from) DST has the effect of compressing (stretching) the day, and thereby potentially having a negative (positive) effect on sleep patterns, the returns for the next trading day will be less (more) than other day returns. Finally, since the 'daylight saving effect' exists in parallel to the 
typical 'weekend effect' the magnitude of the change to (and from) DST will be larger (smaller) than the expected (negative) weekend effect.

Two approaches are used to test these hypotheses. The first involves a descriptive analysis of the mean returns and tests of equality of these means using parametric analysis following Kamstra et al. (2000). As a rule, the mean return for the start of daylight saving is expected to be negative and less than the (negative) return for other weekends, while the mean return for the end of daylight saving can be either negative or positive, though the mean return should be higher than that for daylight saving or other weekends. The second is a regression-based approach where daily market returns are regressed against variables indicating the presence of daylight saving and weekend effects:

$$
R T N_{t}=\beta_{0}+\beta_{1} W K D_{t}+\beta_{2} S T T_{t}+\beta_{3} E N D_{t}+\varepsilon_{t}
$$

where $R T N_{t}$ is the daily Monday to Friday market return at time $t, S T T$ is a dummy variable that equals one on a Monday following a weekend when DST started, END a dummy variable that equals one on a Monday following a weekend when DST ended, $W K D$ a dummy variable that equals one for all other Mondays, $\beta_{i}$ are coefficients to be estimated and $\varepsilon$ is the error term. This approach follows that used by Pinegar (2002). Following the hypotheses presented, the signs on the coefficients for WKD and STT are both expected to be negative, though the magnitude of STT is hypothesised to be larger than WKD, while the hypothesised sign on the coefficient for $E N D$ is positive. Augmented Dickey-Fuller (ADF) tests (with trend and intercept) reject the null hypothesis of a unit root and we conclude that both the price (test statistic $=-30.1679$, $p$-value $=0.0000$ ) and accumulation (test statistic $=-30.1415, p$-value $=0.0000$ ) return series are stationary and suitable for regression-based analysis.

\section{Empirical Findings}

Table 2 presents the summary of descriptive statistics for daily market returns. These are categorised according to the daylight saving and weekend effects hypothesised: namely, (i) non-DST starting or ending weekends, (ii) DST starting weekends common to NSW and VIC, (iii) DST ending weekends common to NSW and VIC, (iv) DST ending weekends for NSW but not VIC, (v) DST ending weekends for VIC but not NSW, (vi) DST starting weekends for other states and territories that were not shared by NSW and/or VIC, (vii) DST ending weekends for other states and territories that that were not shared by NSW and/or VIC, and (viii) all other days. Price returns are depicted in the upper portion of Table 1, while accumulation returns (including dividends and capitalisation changes) are presented in the lower portion. Sample means, trimmed means, medians, standard deviations, minimums, maximums, skewness and kurtosis are reported. Tests of equality of means are also included, comparing the mean returns for weekend and DST-weekend returns to other day returns and for other day and DST-weekend returns to weekend returns. 
TABLE 2

DESCRIPTIVE ANALYSIS OF DAILY RETURN DATA

\begin{tabular}{|c|c|c|c|c|c|c|c|c|c|c|c|c|c|}
\hline & \multirow{2}{*}{$\begin{array}{r}\text { Number } \\
4870\end{array}$} & \multirow{2}{*}{$\begin{array}{c}\text { Mean } \\
0.00039\end{array}$} & \multirow{2}{*}{$\begin{array}{c}\begin{array}{c}\text { Trimmed } \\
\text { Mean }\end{array} \\
0.00049\end{array}$} & \multirow{2}{*}{$\begin{array}{c}\text { Median } \\
0.00036\end{array}$} & \multirow{2}{*}{$\begin{array}{c}\text { Std. } \\
\text { Deviation }\end{array}$} & \multirow{2}{*}{$\begin{array}{r}\text { Minimum } \\
-0.24995\end{array}$} & \multirow{2}{*}{$\begin{array}{r}\text { Maximum } \\
0.06254\end{array}$} & \multirow{2}{*}{$\begin{array}{r}\text { Skewness } \\
-4.35098\end{array}$} & \multirow{2}{*}{$\begin{array}{c}\text { Kurtosis } \\
113.37800\end{array}$} & \multicolumn{2}{|c|}{$\begin{array}{c}\text { Other Days } \\
t \text {-tests }\end{array}$} & \multicolumn{2}{|c|}{$\begin{array}{c}\text { Weekend } \\
t \text {-tests }\end{array}$} \\
\hline Other Days & & & & & & & & & & - & - & -0.707 & $(0.240)$ \\
\hline Weekend & 1148 & 0.00017 & 0.00036 & 0.00000 & 0.00965 & & & -0.63299 & & 0.707 & $(0.240)$ & - & - \\
\hline NSW \& VIC Start & 24 & -0.00204 & 0.00018 & -0.00011 & 0.01483 & & & & & 1.277 & & 1.098 & $.136)$ \\
\hline$\cdot \stackrel{\varrho}{\Xi}$ NSW \& Vic End & 19 & 0.00182 & 0.00140 & & & & & & & -0.672 & & -0.740 & \\
\hline$\Xi$ NSW End & 4 & 0.00 & 0.00333 & 0.00492 & 0.00649 & 568 & & 243 & & -0.591 & $(0$. & -0.612 & $(0.270)$ \\
\hline Ð VIC End & 4 & 0.0 & 512 & 760 & 730 & & & 021 & 37 & -0.955 & (0.1 & -0.961 & $(0.169)$ \\
\hline Other State Start & 11 & & -0.0 & & & & & & & 1.272 & & 1.144 & $(0.127)$ \\
\hline Other State E & 8 & & & & & & & & & & & 1.610 & \\
\hline$\times$ Other Days & & & & & & & & & & - & - & 0.005 & $(0.498)$ \\
\hline Ð Weekend & 1148 & 51 & 0.00065 & & 986 & & & & & -0.005 & $(0.49$ & - & - \\
\hline$\cdot \stackrel{\varrho}{\Xi} \mathrm{NSW}$ and VIC Start & 24 & -0.00267 & -0.00042 & -0.00005 & 0.01591 & -0.06368 & 0.01323 & -2.85455 & 039 & 0.976 & $(0.170)$ & 1.537 & $(0.063)$ \\
\hline.$\stackrel{\Xi}{\Xi} \mathrm{NSW}$ and Vic End & 19 & 0.00213 & 0.00158 & & & & & & & -0.763 & & -0.712 & $(0.239)$ \\
\hline 总 & 4 & 0.00336 & 0.00358 & & 0.00658 & & & & & -0.618 & & -0.578 & $(0.282)$ \\
\hline$\equiv \Xi \mathrm{VIC}$ End & 4 & 0.00514 & 0.00545 & & & & & & & -1.004 & & -0.940 & $(0.174)$ \\
\hline & 11 & & & & & & & & & & & 1.271 & $(0.100)$ \\
\hline Other State End & 8 & -0.00506 & -0.00470 & -0.00216 & 0.00797 & -0.01958 & 0.00298 & -0.91135 & -0.23699 & 1.704 & $(0.045)$ & 1.594 & $(0.056)$ \\
\hline
\end{tabular}

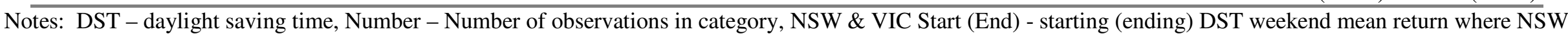

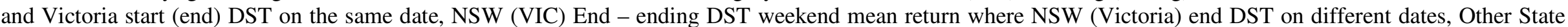

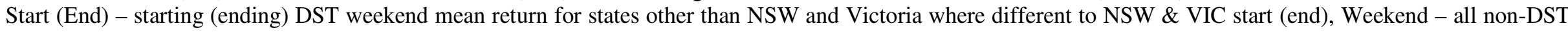

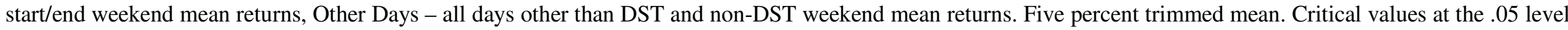

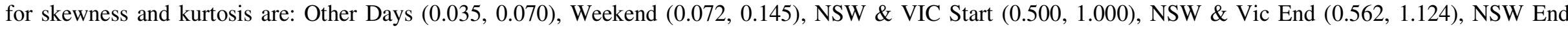

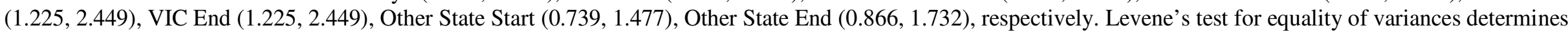

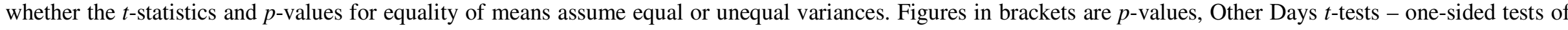

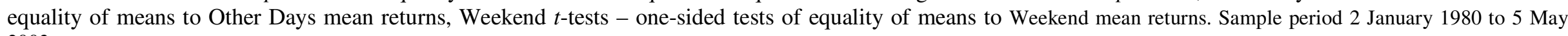
2003. 


\subsection{Parametric Tests of Return Differences for Daylight Saving Weekends}

At first impression, there appears to be some evidence of both the weekend and daylight saving effects in the Australian stock market. In terms of price returns, the mean weekend return (0.00017) is less that of other days (0.00039) while the mean DST starting returns are negative for both NSW and VIC (-0.00204) and other states (0.00317 ) and generally positive for the DST ending returns (NSW and VIC 0.00182, NSW 0.00313, VIC 0.00481 and other states -0.00534). These mean price returns are broadly comparable to mean accumulation returns with the exception that the starting DST returns for NSW are no longer negative.

However, the $t$-tests comparing these mean returns to other days and weekends indicate that few of these differences are statistically significant. The starting DST mean price return is significantly less than other days at the .10 level suggesting that the mean return for Mondays following the introduction of DST in NSW and VIC is six times less than other days, while the return for other states starting DST is about thirteen times less. But these mean differences are no longer significant when specified in terms of returns on the accumulation index. In that instance, only the mean return for other states starting and ending DST are significant (at the .10 and .05 levels, respectively) suggesting mean accumulation returns are between six and nine times less for Mondays following the starting and ending of DST in states other than NSW and VIC where such dates differ.

Significance tests for the differences of means as compared to weekend returns offer a similar picture. For the price index, only the mean returns for other states ending DST is significant at a conventional level but does not conform to the hypothesised direction, whereas in the accumulation index the start and end of DST in states and dates other than NSW and VIC are also significant at the .10 level. In sum, the tests of differences in means show that price returns for Mondays following the introduction of DST are less than the returns for others days but only where DST has started on the same day in both NSW and VIC or where another state or territory has introduced DST on a day that differs from NSW and VIC. For accumulation returns, the mean return is less for Mondays following both the start or ending of DST in a state other than NSW and VIC. Lastly, the mean return for DST starting weekends in accumulation terms and DST ending weekends in price and accumulation returns is significantly less than other weekend returns, but only for DST starting and ending dates outside of NSW and/or VIC.

\subsection{Regression-based Analysis of the Daylight Saving Effect}

The estimated coefficients and standard errors of the parameters detailed in (1) are presented in Table 3. The upper portion of Table 3 is where the dependent variable is specified as daily Monday to Friday price returns, while the lower portion details the results of regressions where daily accumulation returns comprise the dependent variable. The independent variables in all instances are dummy variables for DST starting $(S T T)$ and ending (END) and other weekends (WKD). However, in the first regression for price and accumulation returns, the dummy variables are identified for all DST starting and ending dates, while in the second regression in each case these are DST starting and ending dates in NSW and/or VIC only. Three different standard 
TABLE 3

ESTIMATED COEFFICIENTS AND STANDARD ERRORS FROM DAYLIGHT SAVING REGRESSION MODELS

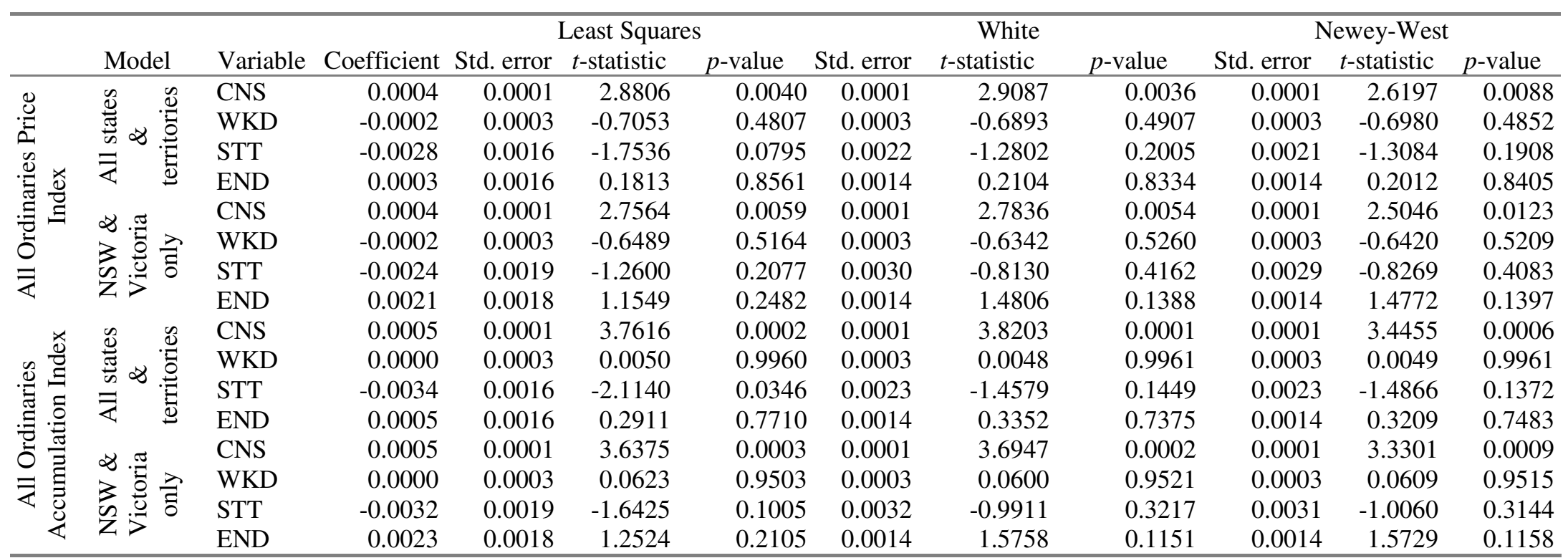

Notes: Dependent variable is daily stock returns on price and accumulation index 2 January 1980 to 5 May 2003. CNS - constant, WKD - non-DST start/end weekend dummy variable, STT - DST starting weekend dummy variable, END - DST ending weekend dummy variable, All States and Territories refers to models including all Australian DST starting and ending weekend dummy variables, NSW and Victoria only model refers to models including only NSW/Victoria DST starting and ending weekend dummy variables. Least squares - standard errors, $t$-statistics and $p$-values from ordinary least squares, White - standard errors, $t$-statistics and $p$-values employing corrections for heteroskedasticity of unknown form following White (1980), Newey-West - standard errors, $t$-statistics and $p$-values employing corrections for heteroskedasticity and autocorrelation of unknown form following Newey and West (1987). 
errors, $t$-statistics and $p$-values are calculated and presented in Table 3 for each of the four regression models. These are standard errors, $t$-statistics and $p$-values obtained by: (i) ordinary least squares (Least Squares), (ii) those employing corrections for heteroskedasticity of unknown form (White), and (iii) those incorporating corrections for heteroskedasticity and autocorrelation of unknown form (Newey-West).

Once again, the signs on the estimated coefficients appear to offer prima facie support for the posited daylight saving effect. The signs on WKD and STT are always negative, with the magnitude of STT being larger, suggesting the presence simultaneously of both the weekend and daylight saving effect market anomalies. That is, the weekend effect is associated with a lower mean return than others days and the start of DST is linked with a larger negative effect as compared to other weekends. The sign on END is likewise consistence with the hypothesis that mean returns following the end of DST are positive, or at least higher, than the mean returns of DST starting and non-starting weekends. However, only in the case of DST starting weekends are the least squares estimates of market returns significant.

Breusch-Godfrey Lagrange multiplier and White's heteroskedasticity tests are used to test for higher order serial correlation and heteroskedasticity in the least squares residuals, respectively. To start with, for both the price (test statistic $=25.9878, p$-value $=0.0000$ ) and accumulation (test statistic $=26.0726, p$-value $=0.0000$ ) returns least squares regressions, the null hypothesis of no serial correlation is rejected and we may conclude the presence of higher order serial correlation in the residuals. Then the null hypothesis of no heteroskedasticity in the least squares residuals fails to be rejected where price (test statistic $=0.1309, p$-value $=0.9417$ ) and accumulation (test statistic $=$ $0.2282, p$-value $=0.8768$ ) returns are specified as the dependent variable and we conclude the presence of heteroskedasticity in the least squares residuals.

After corrections are made for heteroskedasticity (White) and heteroskedasticity and autocorrelation (Newey-West) none of the parameters in Table 1 are significant at any conventional level, irrespective of whether market returns are specified in price or accumulation terms, or whether the transition weekends are in all Australian states and territories or only NSW and VIC. On average, weekend returns that follow the start or end of daylight saving time are not abnormally high or low when compared to other weekends or other days of the week. Furthermore, there is no significant difference between weekend returns as defined (Friday-Monday) and daily returns MondayTuesday, Tuesday-Wednesday, Wednesday-Thursday and Thursday-Friday.

\section{Concluding Remarks and Policy Recommendations}

The present study employs parametric analysis to test for the 'daylight saving effect' market anomaly in the Australian stock market. At first there would appear to be some empirical evidence to support the conjecture that the transition to (and from) daylight saving, as variously defined, is associated with a lower (higher) mean market return than either other weekends or other days. However, after adjustments are made for heteroskedasticity and/or autocorrelation, neither the transition to daylight saving nor the movement from daylight saving is associated with returns that are statistically significantly different from other days, let alone other weekends. These results lie counter to the US, UK and Canadian findings of Kamstra et al. (2000, 2002) but are 
similar to the results of Pinegar (2002, p. 1255) who also found that the hypothesis that "...mean weekend returns are significantly lower following changes in daylight-saving vis-à-vis other weekends is not robust". Indeed, there would also appear to be no evidence in this study to support even the well-investigated hypotheses underlying the weekend effect market anomaly. Daylight saving in Australia may be opposed on a number of policy grounds, but it would appear that adverse affects on capital markets should not be one of them.

Of course, the sleep desynchronosis linked with the transition to and from daylight saving may have a role to play in financial markets that has not been investigated here. All of these indicate future directions for research. One possibility follows the suggestion of Pinegar (2002) that changes in sleep patterns may amplify the impact of negative news and that the true impact of daylight saving, or indeed any other source of sleep disturbance, may be measured by how daylight saving transition weekends affect the magnitude of positive and/or negative changes, rather than positive and/or negative changes themselves.

Another possibility is that the adjustment process to daylight saving may be slower than that hypothesised, and that the full effect of sleep desynchronosis may be felt at less significance over several days rather than the twenty-four hours employed here. Lambe and Cummings (2000), for example, point out that the adjustment process in daylight saving may be longer than jet lag because of the absence of new external reference points to the change in time. Finally, it may well be the case that the daylight saving effect, like many other market anomalies, is felt more keenly in small companies than large. Since this study uses market-weighted stock indices as against price or equal-weighted market indices or small cap sector indices, such differences may well be obscured.

\section{REFERENCES}

Agrawal, A. and D.L. Ikenberry (1994) "The Individual Investor and the Weekend Effect”, Journal of Financial and Quantitative Analysis, 29, pp. 263-277.

Bick, P.A. and A.L. Hannah (1986) "The Effect of Daylight Saving on the Incidence of Psychiatric Presentation", Royal College of Psychiatrists Annual Meeting, University of Southampton: Royal College of Psychiatrists.

Chang, E.C., J.M. Pinegar and R. Ravichandran (1993) "International Evidence on the Robustness of the Day-of-the-Week Effect", Journal of Financial and Quantitative Analysis, 28, pp. 497-513.

Chang, E.C., J.M. Pinegar and R. Ravichandran (1998) "U.S. Day-of-the-Week Effects and Assymetric Responses to Macroeconomic News", Journal of Banking and Finance, 22, pp. 513534.

Commonwealth Bureau of Meteorology (2003), http://www.bom.gov.au/, accessed May 2003.

Coren, S. (1996a) "Accidental Death and the Shift to Daylight Savings Time", Perception and Motor Skills, 83, pp. 921-922.

Coren, S. (1996b) "Daylight Saving Time and Traffic Accidents", New England Journal of Medicine, 334, pp. 924.

Kamstra, M.J., L.A. Kramer and M.D. Levi (2000), "Losing Sleep at the Market: The Daylight Saving Anomaly", American Economic Review, 90, pp. 1005-1011.

Kamstra, M.J., L.A. Kramer and M.D. Levi (2002), "Losing Sleep at the Market: The Daylight Saving Anomaly - Reply", American Economic Review, 92, pp. 1257-1263.

Lambe, M. and P. Cummings (2000) "The Shift To and From Daylight Savings Time and Motor Vehicle Crashes", Accident Analysis and Prevention, 32, pp. 609-611. 
Newey, W.K. and K.D. West (1987) "A Simple, Positive Semi-Definite, Heteroskedasticity and Autocorrelation Consistent Covariance Matrix", Econometrica, 55, pp. 703-708.

Pinegar, J.M. (2002) "Losing Sleep at the Market: Comment", American Economic Review, 92, pp. 1251-1256.

Shapiro, C.M. F. Blake, A. Fossey and B. Adams (1990) "Daylight Saving Time in Psychiatric Illness", Journal of Affective Disorders, 19, pp. 177-181.

Sullivan, J.M. and M.J. Flannagan (2002) "The Role of Ambient Light in Fatal Crashes: Inferences from Daylight Saving Time Transitions", Accident Analysis and Prevention, 34, pp. 487-498.

Varughese, J. and R.P. Allen (2001) "Fatal Accidents Following Changes in Daylight Savings Time: The American Experience", Sleep Medicine, 2, pp. 31-36.

Wang, K., Y. Li and J. Erickson (1997) “A New Look at the Monday Effect”, Journal of Finance, 52, pp. 2171-2186.

Waterhouse, J., T. Reilly and G. Atkinson (1997) “Jet Lag”, Lancet, 350, pp. 1611-1616.

White, H.L. (1980) "A Heteroskedasticity-Consistent Covariance Matrix Estimator and a Direct Test for Heteroskedasticity", Econometrica, 48, pp. 817-838.

This paper was later published as:

Worthington, Andrew (2003) Losing Sleep At The Market: An Empirical Note On The Daylight Saving Anomaly In Australia. Economic Papers 22(4):pp. 83-93. 